Supporting Information

\title{
Observable Electrochemical Oxidation of Carbon Promoted by Platinum Nanoparticles
}

\author{
Zongkui Kou, Kun Cheng, Hui Wu, Ronghui Sun, Beibei Guo, Shichun $\mathrm{Mu}^{*}$ \\ State Key Laboratory of Advanced Technology for Materials Synthesis and Processing, \\ Wuhan University of Technology, Wuhan 430070, China. \\ *Corresponding author. Tel: +86 27 87651837. *E-mail: msc@whut.edu.cn(Shichun Mu)
}




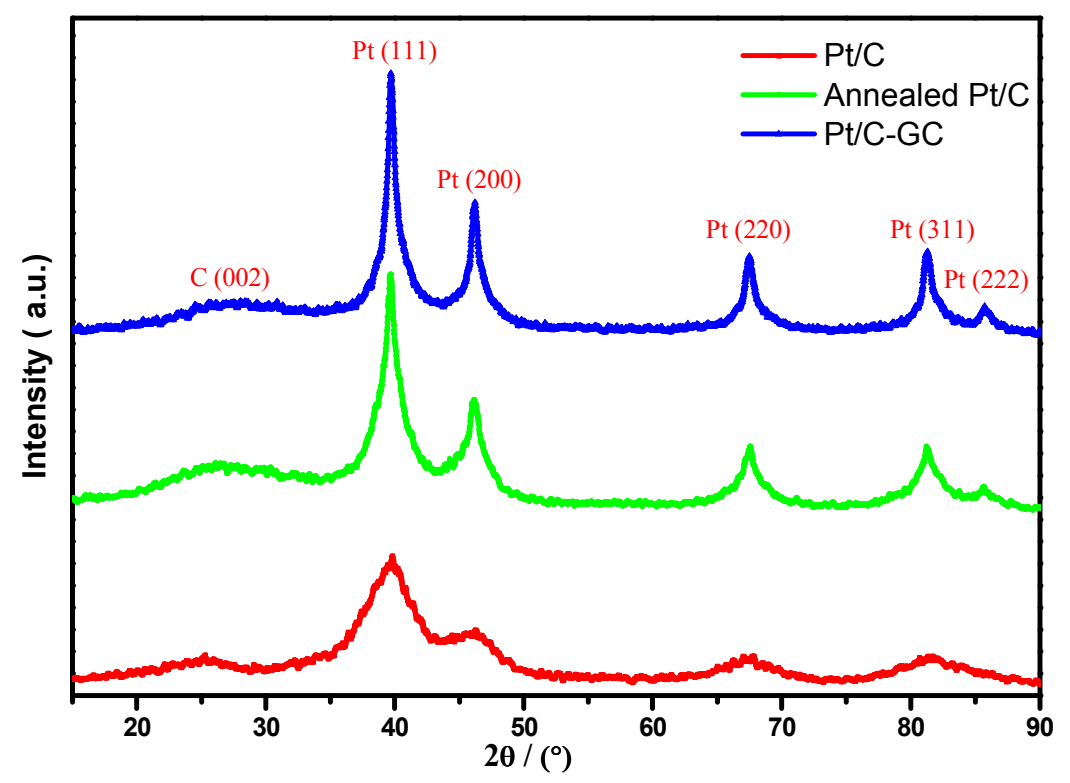

Figure S1. XRD patterns. $\mathrm{Pt} / \mathrm{C}$ (red), annealed $\mathrm{Pt} / \mathrm{C}$ (green), and $\mathrm{Pt} / \mathrm{C}-\mathrm{GC}$ (blue). The results confirm that the Pt nanoparticles have typical face-centered cubic (fcc) crystal structure ${ }^{1}$. 

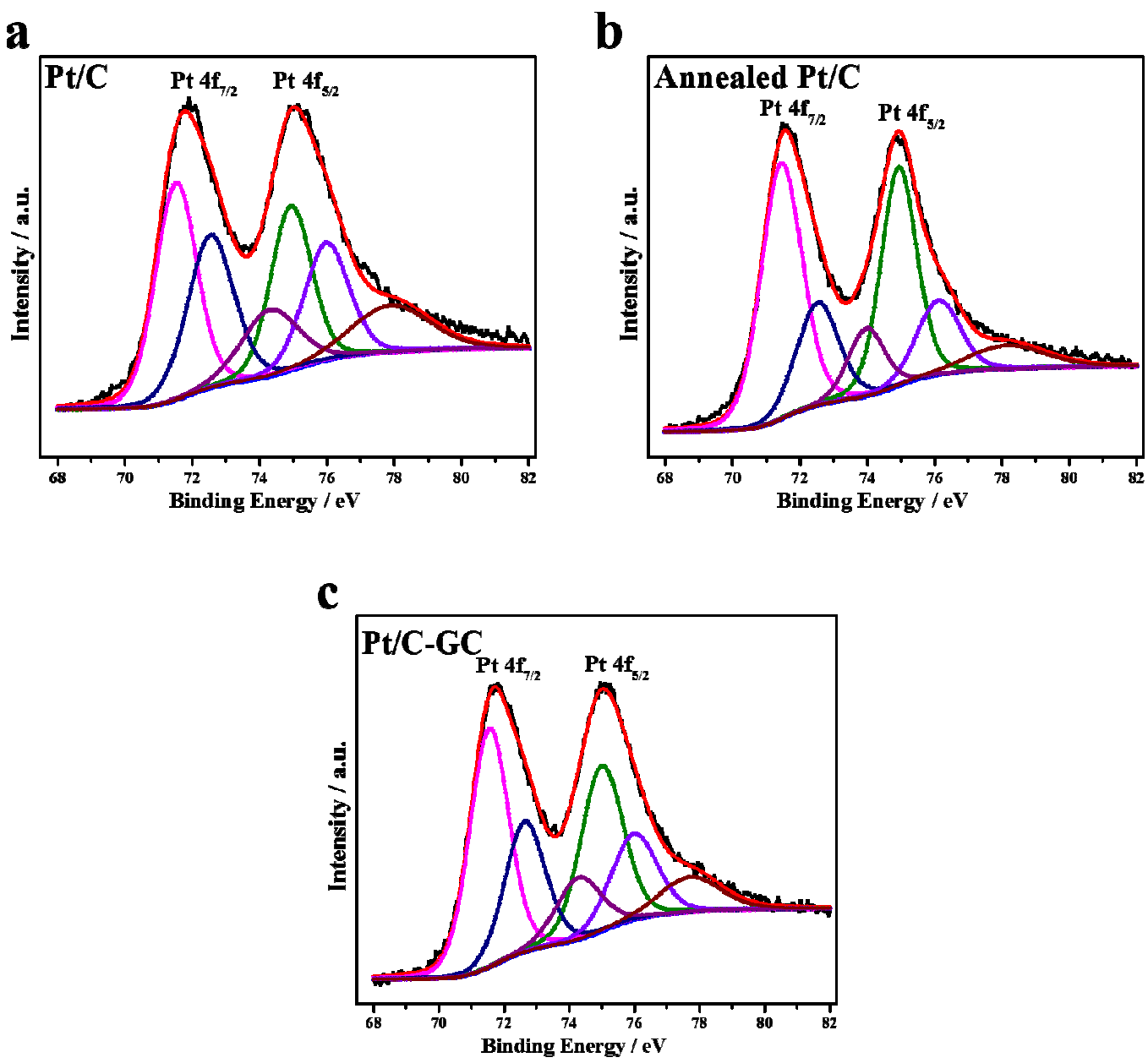

Figure S2. Pt (4f) XPS spectra of various nanomaterials. (a) $\mathrm{Pt} / \mathrm{C}$, (b) annealed $\mathrm{Pt} / \mathrm{C}$, and (c) Pt/C-GC. 

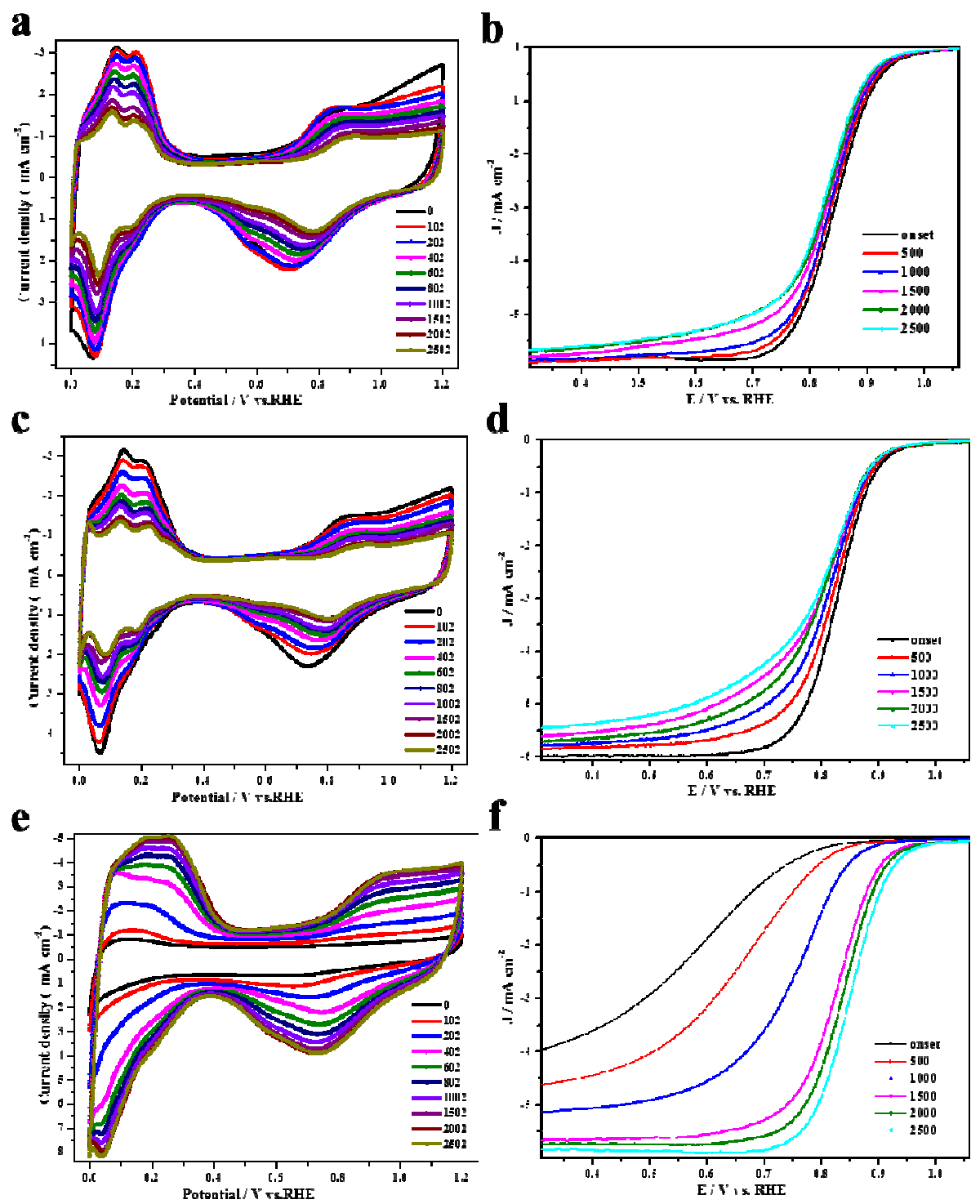

Figure S3. Cyclic voltammograms (a, c and e) along with cycle number (0-2500) in $0.1 \mathrm{~mol} / \mathrm{L} \mathrm{HClO}_{4}$ for all nanomaterials during the accelerated potential cycling test. (a) $\mathrm{Pt} / \mathrm{C}$, (c) annealed $\mathrm{Pt} / \mathrm{C}$, and (e) $\mathrm{Pt} / \mathrm{C}-\mathrm{GC}$. Scanning rate: $50 \mathrm{mV} / \mathrm{s}$; Test temperature: $25^{\circ} \mathrm{C}^{2}$. Current-potential curves for ORR at $0.9 \mathrm{~V}$ along with cycle number. (b) $\mathrm{Pt} / \mathrm{C}$, (d) annealed $\mathrm{Pt} / \mathrm{C}$, and (f) $\mathrm{Pt} / \mathrm{C}-\mathrm{GC}$. Scanning rate: $5 \mathrm{mV} / \mathrm{s}$ (test) and $100 \mathrm{mV} / \mathrm{s}$ (acceleration); Test temperature: $25{ }^{\circ} \mathrm{C}$. 

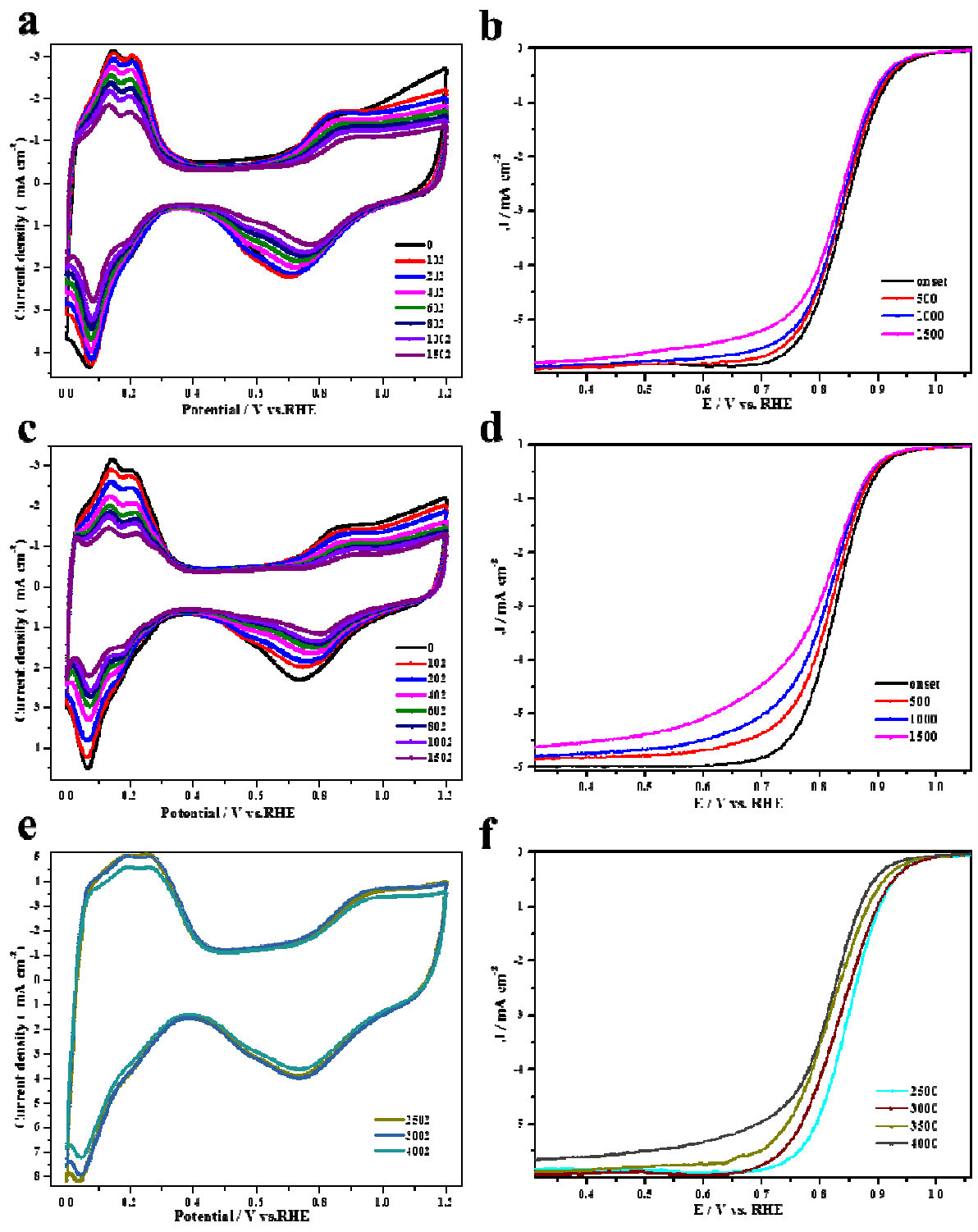

Figure S4. Cyclic voltammograms (a, $\mathrm{c}$ and e) along with cycle number (0-1500) for $\mathrm{Pt} / \mathrm{C}$ and annealed Pt/C, 2500-4000 for $\mathrm{Pt} / \mathrm{C}-\mathrm{GC}$ in $0.1 \mathrm{~mol} / \mathrm{L} \mathrm{HClO}_{4}$ for all nanomaterials during the accelerated potential cycling test. (a) $\mathrm{Pt} / \mathrm{C}$, (c) annealed $\mathrm{Pt} / \mathrm{C}$, and (e) $\mathrm{Pt} / \mathrm{C}-\mathrm{GC}$. Scanning rate: $50 \mathrm{mV} / \mathrm{s}$; Test temperature: $25{ }^{\circ} \mathrm{C}$. Current-potential curves for ORR at $0.9 \mathrm{~V}$ along with cycle number (0-1500) for $\mathrm{Pt} / \mathrm{C}$ and annealed $\mathrm{Pt} / \mathrm{C}, 2500-4000$ for $\mathrm{Pt} / \mathrm{C}-\mathrm{GC}$ in $0.1 \mathrm{~mol} / \mathrm{L} \mathrm{HClO}_{4}$ for all nanomaterials during the accelerated potential cycling test: (b) $\mathrm{Pt} / \mathrm{C}$, (d) annealed $\mathrm{Pt} / \mathrm{C}$, and (f) Pt/C-GC. Scanning rate: $5 \mathrm{mV} / \mathrm{s}$ (test) and $100 \mathrm{mV} / \mathrm{s}$ (acceleration); Test temperature: $25^{\circ} \mathrm{C}$. 

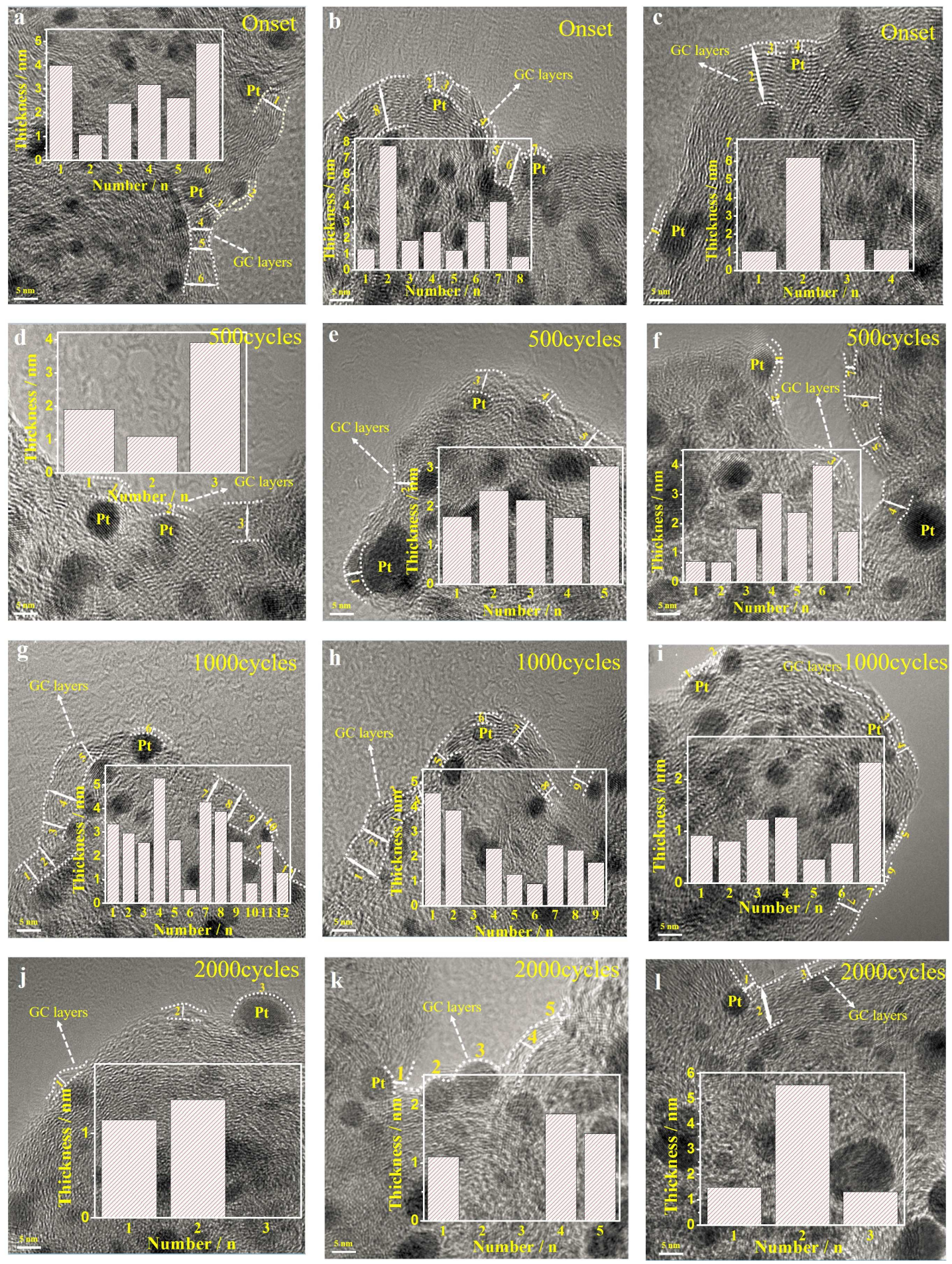

Figure S5. HRTEM images of Pt/C-GC on thickness changes of GC layers

during the ADT process. (a-c) onset, (d-f) 500 cycles, (g-i) 1000 cycles, (j-l) 2000 cycles. These images were used in statistical thickness changes of GC layers. 
Table S1. Binding energy $[\mathrm{BE}(4 \mathrm{f} 7 / 2), \mathrm{eV}]$ and atomic percentages (\%) of different $\mathrm{Pt}\left[\mathrm{Pt}(0), \mathrm{Pt}^{2+}\right.$ and $\left.\mathrm{Pt}^{4+}\right]$ obtained from $\mathrm{Pt}(4 \mathrm{f})$ XPS spectra.

\begin{tabular}{cccc}
\hline Sample & $\mathrm{Pt}(0)$ & $\mathrm{Pt}(\mathrm{II})$ & $\mathrm{Pt}(\mathrm{IV})$ \\
& $\mathrm{BE}=71.5$ & $\mathrm{BE}=72.6$ & $\mathrm{BE}=74.3$ \\
\hline $\mathrm{Pt} / \mathrm{C}$ & 44.64 & 35.71 & 19.65 \\
Annealed $\mathrm{Pt} / \mathrm{C}$ & 61.40 & 24.56 & 14.04 \\
$\mathrm{Pt} / \mathrm{C}-\mathrm{GC}$ & 53.57 & 30.36 & 16.07 \\
\hline
\end{tabular}




\section{References:}

(S1) Joo, S. H. ; Choi, S. J. ; Oh, I. ; Kwak, J. ; Liu, Z. ; Terasaki, O. ; Ryoo, R. Ordered nanoporous arrays of carbon supporting high dispersions of platinum nanoparticles. Nature 2001, 412, 169-172.

(S2) Garsany Y. ; Baturina O. A. ; Swider-Lyons K. E. ; Kocha S. S. Experimental methods for quantifying the activity of platinum electrocatalysts for the oxygen reduction reaction. Anal. Chem. 2010, 82, 6321-6328. 